\title{
Reliability Assessment of Advanced Materials and Structures*
}

\author{
Soon-Bok LEE** \\ **Department of Mechanical Engineering \\ Korea Advanced Institute of Science and Technology \\ 335 Gwahak-ro, Yuseong-gu, Daejeon 305-701, Korea \\ sblee@kaist.ac.kr
}

\begin{abstract}
This paper discusses the reliability assessment of advanced structures such as micro/nano structures, electronics packaging for modern electronic devices, high temperature structures such as nuclear power plants, rocket engines for space application. Characterization of advanced materials includes free-standing electrodeposited nano-crystalline nickel thin film, polysilicon, and piezoelectric thin film for MEMS/nano structures. Lead-free solders under pseudo-power cyclic thermal loading, impact loading and mechanical bending loading were evaluated for reliability assessment of the advanced electronic packaging. Reliability assessment of $\mathrm{Cu} / \mathrm{SnAg}$ double bump structures was performed for the $150 \mu \mathrm{m}$ pitch flip chip electronic packaging application. The $316 \mathrm{~L}$ austenitic stainless steel for high-temperature components application such as in the primary side of liquid metal cooled fast breeder reactor (LMFBR) was tested under various temperatures where dynamic strain ageing occurs. The effects of dynamic strain ageing on the tensile behavior and fatigue behavior of 316L stainless steel have been identified.
\end{abstract}

Key words: Reliability, Thin Film, Electronics Packaging, Impact Loading, High Temperature Structures, Dynamic Strain Ageing

\section{Introduction}

Modern society requires high speed and mass transportation, fast communication with hand held devices, and also environment-friendly materials. The technology of MEMS fabrication and study of nano structures have been greatly advanced. However there still exist vast barriers to the actual engineering applications. One of the most significant barriers is the long term reliability of the micro/nano structures. Material properties of micro/nano structures are different from those of bulk materials ${ }^{(1)(2)(3)}$. Material characterization of thin film for MEMS/nano structures is one of the building blocks for the reliability assessment. Nano-indenter has been used to get the Young's modulus of materials in a very simple way $^{(4)}$ but other tensile properties are required. For such reason, a new micro-tensile testing has been developed, where the difficulty of measuring the strain on the micro-scale specimens has been overcome with a dual micro-scope ${ }^{(1)}$. The mechanical properties of PZT actuator has also been characterized with a bulge testing ${ }^{(5)}$ by measuring the shape of deformation with Twyman-Green interferometry ${ }^{(6)(7)(8)}$. The mechanical properties of free standing electrodeposited Ni-thin film are also characterized for different annealing temperature to incorporate the manufacturing process of MEMS structures such as DVD, and various sensors ${ }^{(9)}$.

For the easy communication at any place and any time, the electronic devices such as

*Received 16 Nov., 2009 (No. e122) [DOI: 10.1299/jmmp.4.639]

Copyright $\odot 2010$ by JSME 
cellular phones become thinner and lighter for portability and also highly integrated with other functions such as camera, music player, and even $\mathrm{TV}^{(10)}$. For this reason electronic packaging technology ${ }^{(11)(12)}$ has been dramatically improved to integrate all such functions in a small portable electronic device. In addition to this trend new materials have to be replaced to avoid the hazard materials such as lead-contained solder materials. The material characteristics of lead-free solder joints ${ }^{(13)(14)(15)(16)(17)}$ are essential for the reliability assessment of for the advanced electronics packaging. Materials used in electronics packaging are silicon chips, plastic printed circuit board, solder joints connecting the chip and PCB. The difference in the coefficient of thermal expansion produces a large shear stress on the solder joints under thermal loading. Cellular phones are subjected to mechanical bending loading ${ }^{(14)}$ by pressing the key pad, and also subjected to impact loading ${ }^{(15)}$ by dropping the device. The life predictions of solder joints under such various loading situations are essential for the reliability evaluation of electronics packaging ${ }^{(14)(15)}$. For the reliability assessment under impact loading, JEDEC standard recommend to drop 50 times from at a constant height. It can be very time consuming and requires high cost to do the repeated dropping test. Yet it can not provide the rigorous life prediction of solder joint level. For such reason a new dropping machine is needed to perform repeated impact loading in a more systematic manner in solder joints level. For the high input/output ratio of interconnections in a thinner and lighter packaging, the pitch of flip chip electronics packaging is needed up to $150 \mu \mathrm{m}$. In such a fine pitch interconnection, the conventional solder joints may produce short circuit. Reliability assessment of $\mathrm{Cu} / \mathrm{SnAg}$ double-bump structure has been performed for the advanced electronics packaging ${ }^{(18)}$. Another advanced packaging structure is achieved with anisotropic conductive film (ACF) which provides the ultra thin electronics device. But interconnections with ACF film are apt to a delamination failure due to the moisture. Moisture affecting the integrity of electronics packaging has to be considered ${ }^{(12)}$.

For fast and mass transportation, the energy saving high efficiency operation leads to high temperature operation of automobile engines and marine engines. Since the structures are operated at the higher temperatures, reliability of such structures became critical issues. To meet such requirement of reliability, proper characterization of high temperature materials are needed. Mechanical properties of four different high temperature materials are studied at various elevated temperatures ${ }^{(19)}$. Dynamic strain aging (DSA) appeared at the high temperature materials. DSA affects the tensile and fatigue properties of high

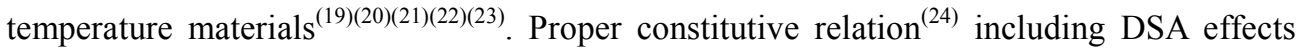
must be considered for the design of high temperature structures.

Since reliability assessment of advanced structures and materials are critical issues in modern society for safety and comport of human life, three different structural groups are briefly discussed. They are micro/nano structures, electronics packaging, and high temperature structures.

\section{Thin Film for Micro/Nano Structures}

\subsection{Material Characterization of Thin Film}

Electroplated nickel thin film manufactured via LIGA process offers the possibility of stronger structures and connectors in microelectromechanical system (MEMS). Material characterization of electroplated nickel thin film for MEMS and nano structures are performed with a customized tensile tester and compared with nano-indenter. In the tensile test, a linear guided motor was used and the applied force was measured using a load cell which measures up to $11.5 \mathrm{~N}$ with resolution of $5 \mathrm{mN}$. The error in stress measurement due to misalignments caused by bending of specimen when it is glued to the grip is estimated 4.5 $\mathrm{MPa}$ by a simple beam theory, which is less than $0.3 \%$ of yield strength. This error can be acceptable. Fig. 1 shows the photo of the micro tensile testing system. 


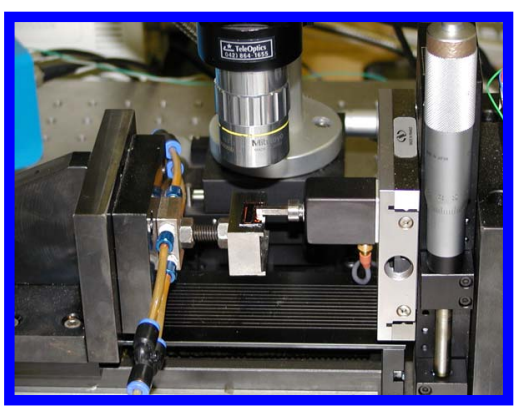

Fig.1 A photo of the micro tensile tester.

Strain was measured with a dual microscope that obtained the displacement of two separated points by the tracking process of the image captured with CCD camera. The detail description of this strain measurement is described elsewhere ${ }^{(1)}$. Specimens were prepared in a same wafer and tested after four month of aging, which reduces the variation of properties caused by fabrication condition and aging effect. The tensile specimen is 15 $\mu \mathrm{m}$ in thickness and $300 \mu \mathrm{m}$ in width. The indentation specimen has the thickness of $15 \mu \mathrm{m}$. Results of tensile test of the electroplated nickel and comparison with bulk nickel and other results by Sharpe ${ }^{(2)}$ and Greek ${ }^{(3)}$ are listed in Table 1.

The Young's modulus is obtained by calculating the slope of the stress-strain curve using a least-squares-fit in the range of $0.2 \%$ strain of the tensile test. Young's modulus was also measured with a nanoindentation. The methodology of Young's modulus measurement by instrumented nanoindentation was followed by the literature ${ }^{(4)}$. The values were averaged through 500 to $900 \mathrm{~nm}$ depth. The results of Young's modulus results at four different locations are 195(1.47), 205(1.93), 214(2.27), 195(1.66) GPa, where the numbers in parenthesis are the standard deviations of measurement of each location. The Young's modulus results by tensile test and nanoindentation results are very close each other.

Table 1 Tensile test results of electroplated thin film and comparison with bulk Ni and other results of different thickness.

\begin{tabular}{|c|c|c|c|c|}
\hline & $\mathrm{E}(\mathrm{GPa})$ & $\mathrm{UTS}(\mathrm{GPa})$ & $\sigma_{\mathrm{y}}(\mathrm{MPa})$ & thickness $(\mu \mathrm{m})$ \\
\hline Thin film (current) & $200 \pm 12$ & $2.56 \pm 0.26$ & $1520 \pm 220$ & 15 \\
\hline Bulk Ni & 207 & 0.317 & 59 & \\
\hline Sharpe et al $^{(2)}$ & $176 \pm 30$ & 0.55 & $320 \pm 30$ & 200 \\
\hline Greek $^{(3)}$ & $231 \pm 12$ & $2.47 \pm 0.07$ & $1550 \pm 50$ & 5 \\
\hline
\end{tabular}

Electrodeposited nanocrystalline nickel thin film specimens were manufactured with lithography. It has $100 \mu \mathrm{m}$ width, $50 \mu \mathrm{m}$ thickness, and $1.2 \mathrm{~mm}$ gage length. Same size of specimen of wrought nickel film was made by chemical etching process for comparison. Fig. 2 shows the tensile behavior of electroplated nickel and wrought nickel. The yield strength and tensile strength of nanocrystalline electroplated thin film are $860 \pm 13 \mathrm{GPa}$, $1412 \pm 27 \mathrm{GPa}$ respectively. Electrodeposited nickel thin film showed strain rate dependency and higher strength than wrought nickel.

MEMS process has multilayer depositions. The deposited thin film can be exposed to high temperature at the additional MEMS process. The sputtering process increases the temperature up to $350{ }^{\circ} \mathrm{C}$ on the base material; plasma enhanced chemical vapor deposition (PECVD) increases up to $400{ }^{\circ} \mathrm{C}$. This influences the crystalline structure and mechanical behavior of the predeposited thin film just like an annealing process. Fig. 3 shows the stress versus strain curve and fractured shape for electrodeposited nickel films annealed in vacuum at $100,200,300,400$ and $500{ }^{\circ} \mathrm{C}$. 


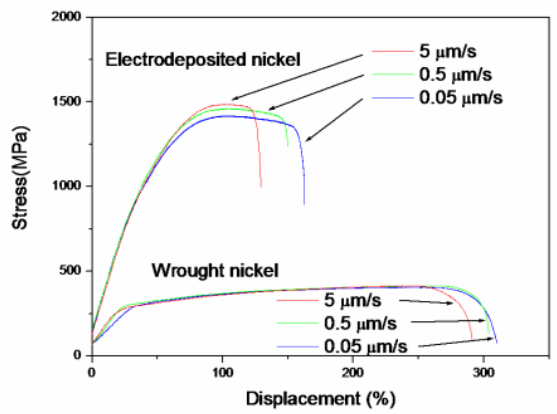

Fig.2 Tensile behavior of electroplated nickel and wrought nickels

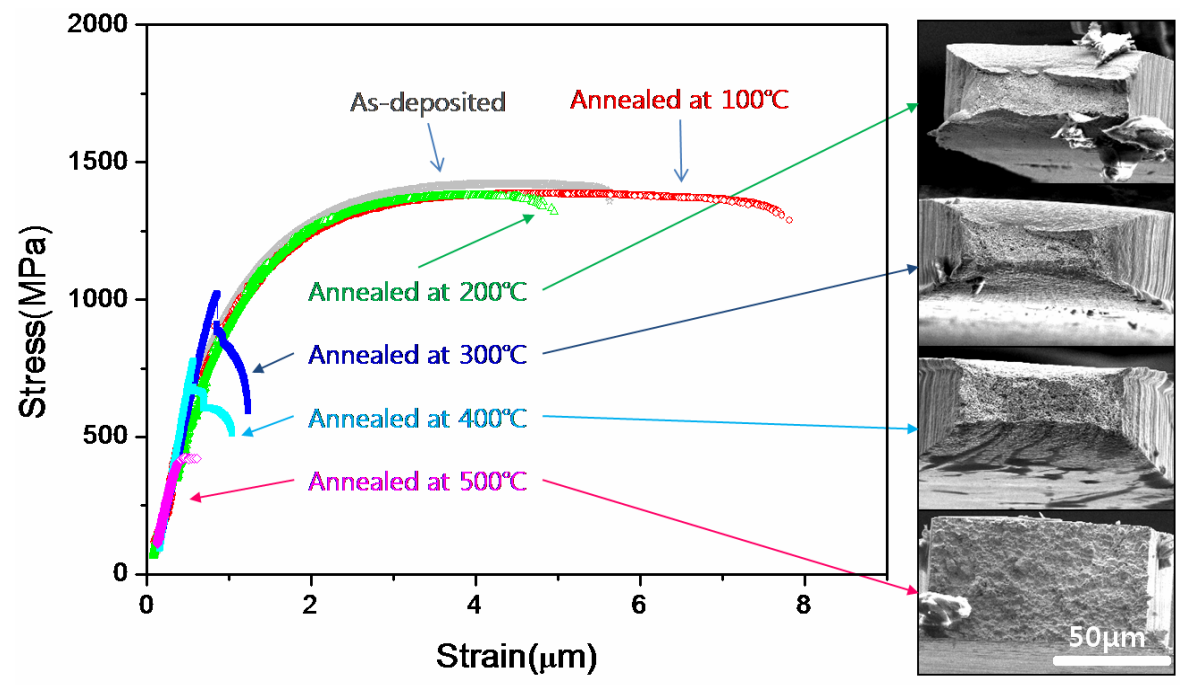

Fig.3 Stress versus strain curve and fractured shape for electrodeposited nickel films annealed at $100,200,300,400$ and $500{ }^{\circ} \mathrm{C}$.

\subsection{Fatigue Behavior of Electrodeposited Nickel Thin Film}

Micro fatigue testing machine were developed for the high cycle fatigue testing of electroplated nickel thin film. Fig. 4 shows a schematic diagram of the micro fatigue testing machine. Fig. 5 shows the fatigue testing results as maximum stress versus cycles to failure of electrodeposited nanocrystalline (nc) nickel and wrought microcrystalline(mc) nickel under $17 \mathrm{~Hz}$ and load ratio, $\mathrm{R}=0.2$.

With the Basquin's high cycle fatigue model ${ }^{(25)}$ and Morrow's mean stress effect $^{(26)}$, the fatigue test results can be expressed as following eq.(1)

$\sigma_{a}=\left(\sigma_{f}^{\prime}-\sigma_{a} \frac{1+R}{1-R}\right)\left(2 N_{f}\right)^{b}$

where $\sigma_{a}=\frac{\Delta \sigma}{2}=$ true stress amplitude

$N_{f}=$ reversals to failure $(2 \mathrm{rev}=1 \mathrm{cycle})$

$\sigma_{f}^{\prime}=$ fatigue strength coefficient 


$$
\begin{aligned}
& b=\text { fatigue strength exponent, }-0.05 \text { to }-0.12 \text { for metal }{ }^{(27)} . \\
& R=\frac{\sigma_{\min }}{\sigma_{\max }}=\text { stress ratio }
\end{aligned}
$$

And the results of fatigue strength coefficient and fatigue strength exponent of nano crystalline and micro crystalline nickel are shown in Table 2. Fatigue tests of the nanocrystalline electrodeposited nickel revealed much stronger fatigue strength than microcrystalline wrought nickel.

Table 2 Fatigue results

\begin{tabular}{|c|c|c|}
\hline Materials & $\begin{array}{r}\text { Fatigue strength } \\
\text { coefficient (MPa), } \sigma_{f}^{\prime}\end{array}$ & $\begin{array}{c}\text { Fatigue strength } \\
\text { exponent, b }\end{array}$ \\
\hline $\mathrm{nc}$ & 1686 & -0.092 \\
$\mathrm{mc}$ & 772 & -0.110 \\
\hline
\end{tabular}

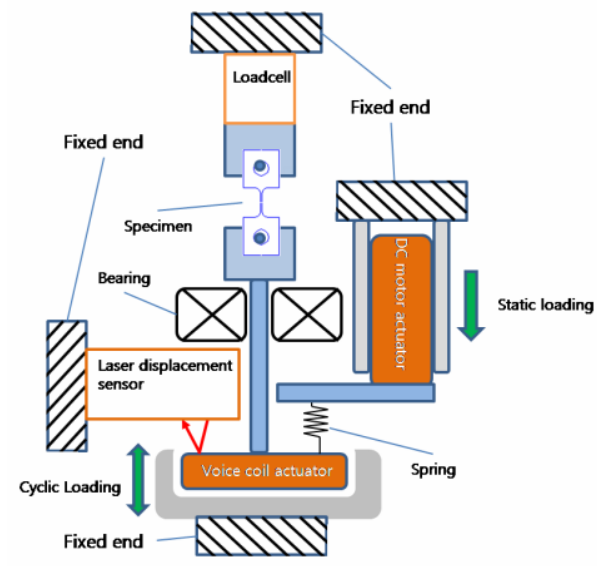

Fig. 4 A schematic diagram of the fatigue testing machine

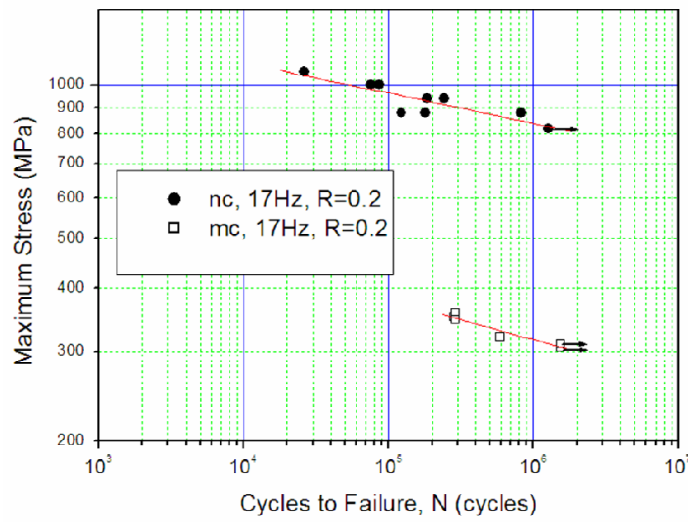

Fig. 5 Maximum Stress versus cycles to failure of electrodeposited nickel

\subsection{Elastic Modulus of Multilayered Thin Films in Piezoelectric Inkjet Head.}

With the rapid development of the drop-on-demand (DOD) inkjet print head, there is a growing demand of using inkjet printing technology not only office printing applications but also in promising industrial applications. Piezoelectric inkjet print head is preferred choice of DOD industrial printing applications because it can handle variety of jetting fluids and provide consistent high performance under harsh working conditions. It can provide the advantage of no contact deposition and is already being utilized effectively in manufacturing processes of liquid crystal display, polyimide alignment layer, chromatic filter, fuel injector of engine, optical interconnects, organic light-emitting devices, etc. ${ }^{(28)}$. In piezoelectric inkjet heads, when an electric pulse is applied to the piezo element placed on the wall of the ink chamber in a multilayer actuator, the vibrating plate deforms to create a pressure wave that causes the ink droplet to be ejected through the nozzle. For the reliable design of the piezoelectric head, the mechanical properties are essential part of the design process however it is difficult to obtain the properties of the actual actuator size. Multilayer 
actuator of a piezoelectric inkjet head consists with polycrystalline silicon (polysilicon) and lead zirconate titanate (PZT). A bulge testing system has been developed to characterize the deformation behaviors and elastic modulus of these multilayered films. In the bulge testing commercial inkjet heads including a few tens of multilayer actuators were directly pressurized by air as shown in Fig.6. The detailed bulge test system is described elsewhere $^{(5)}$. The schematic bulge shape by pressure loading is shown in Fig.7. The corresponding deflections were measured via full-field optical measurement techniques. The polycrystalline silicon with reflective surface was measured with Twyman-Green interferometry shown in Fig.8. It has a basic resolution of $316.5 \mathrm{~nm} /$ fringe and can be enhanced up to $50 \mathrm{~nm} /$ fringe after phase shifting. Fig.9 shows the fringe pattern of six membrane cells of polycrystalline silicon (polysilicon) at the pressure of 5.75bar. An analytic solution derived from a thin-plate theory and the result was compared with the experimental data to evaluate the elastic modulus of individual film. The result showed that the elastic modulus of polysilicon is around $110 \mathrm{GPa}$. PZT films were measured with an ESPI system, a commercial one (Dantec-Ettemeyer Q-300). The system provides the sensitivity up to $23 \mathrm{~nm} /$ fringe by phase shifting. The elastic modulus of the PZT film was found around 49GPa. Young's modulus of polysilicon and PZT obtained by these optical techniques were consistent with the nanoindentation results.

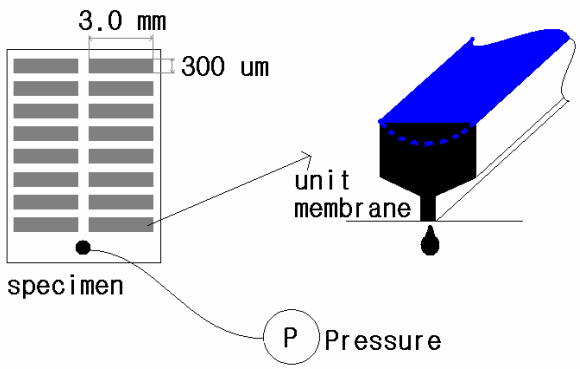

Fig.6 Bulge test specimen of PZT ink jet print head

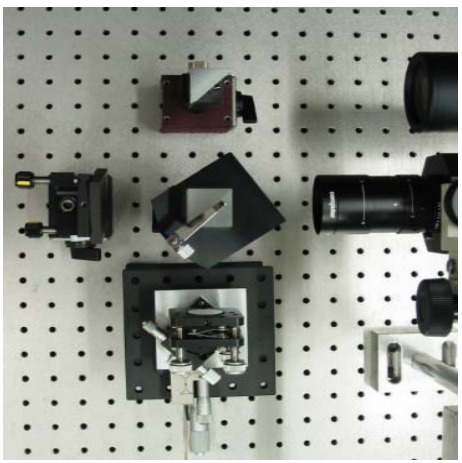

Fig. 8 Twyman-Green Interferometry setup

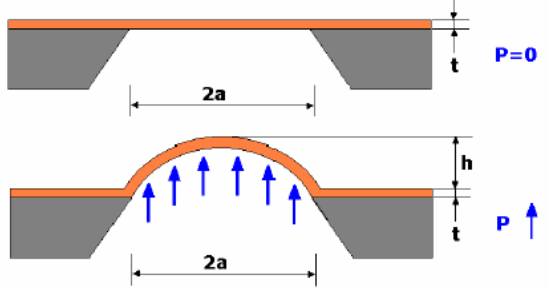

Fig.7 Schematic diagram of a bulge shape by pressure.

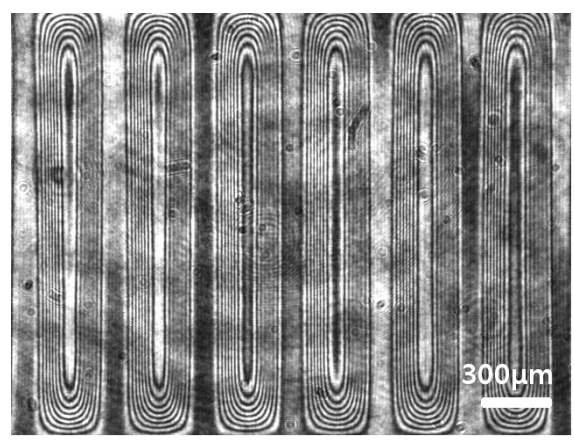

Fig.9 Fringe pattern of six membrane cells at the pressure of 5.75 bars.

\section{Electronics Packaging}

Environmental concerns on toxicity of lead have resulted in legislation forbidding the use of lead in microelectronics products. Low-cycle, lab-shear fatigue behaviour of Sn-based, $\mathrm{Pb}$-free solder alloys has been studied to replace the tin-lead eutectic alloys ${ }^{(13)}$. Lead-free solders for advanced electronic packaging are characterized with mechanical, 
thermal, and impact loading situations as described by Kim and Lee ${ }^{(14)(15)}$ Pseudo-power cycling tester ${ }^{(16)}$ for thermal loading, cyclic bending tester ${ }^{(17)}$ for mechanical bending test, and impact-fatigue tester ${ }^{(15)}$ for impact loading have been successfully developed and generated the necessary test results for lead-free solder joints of electronic packaging. Thermal cyclic reliability and failure analysis of $\mathrm{Cu} / \mathrm{SnAg}$ double-bump structure for next generation packaging were successfully investigated for the long-term reliability enhancement. Warpage of flip-chip packages with anisotropic conductive film under thermal and humidity environment were measured with optical method and compared with FEM analysis as descried by Yoon et al. ${ }^{(12)}$. Moiré Interferometry has been extensively utilized in reliability assessment of the micro electronics packaging such as measurement of creep and relaxation behavior of wafer level CSP assembly ${ }^{(10)}$, and health monitoring for electronic package using a simple Moiré interferometry ${ }^{(11)}$. Fatigue and fracture behavior of solder joints in electronics packaging under mechanical and thermal loads have been reported $^{(29)}$. Some details for impact behaviors and comparison of various loading, and $\mathrm{Cu} / \mathrm{SnAg}$ double bump structure will be described as following.

\subsection{Impact Loading}

The use of portable devices, such as cellular phones, personal digital assistants (PDAs), portable multimedia players, and notebook computers has increased. In the portable devices, the impact load due to dropping is the major failure mechanism. Assessment of resistance against drop-impact force is required to predict the life of electronic package. A novel micro impact-fatigue tester has been developed to overcome the drawback of conventional impact test. The impact fatigue test machine consists of electromagnetic actuator, an impact-pin, a load cell, a displacement sensor, and a main frame. Detailed description of this machine can be found elsewhere ${ }^{(15)}$. A lead-free solder $(96.5 \mathrm{Sn} 4.0 \mathrm{Ag} 0.5 \mathrm{Cu})$ was tested with the micro impact fatigue tester. Fig. 10 shows the repeated impact load of $40 \mathrm{~N}$ and corresponding deformation and cracks initiated at the corner of solder joints.

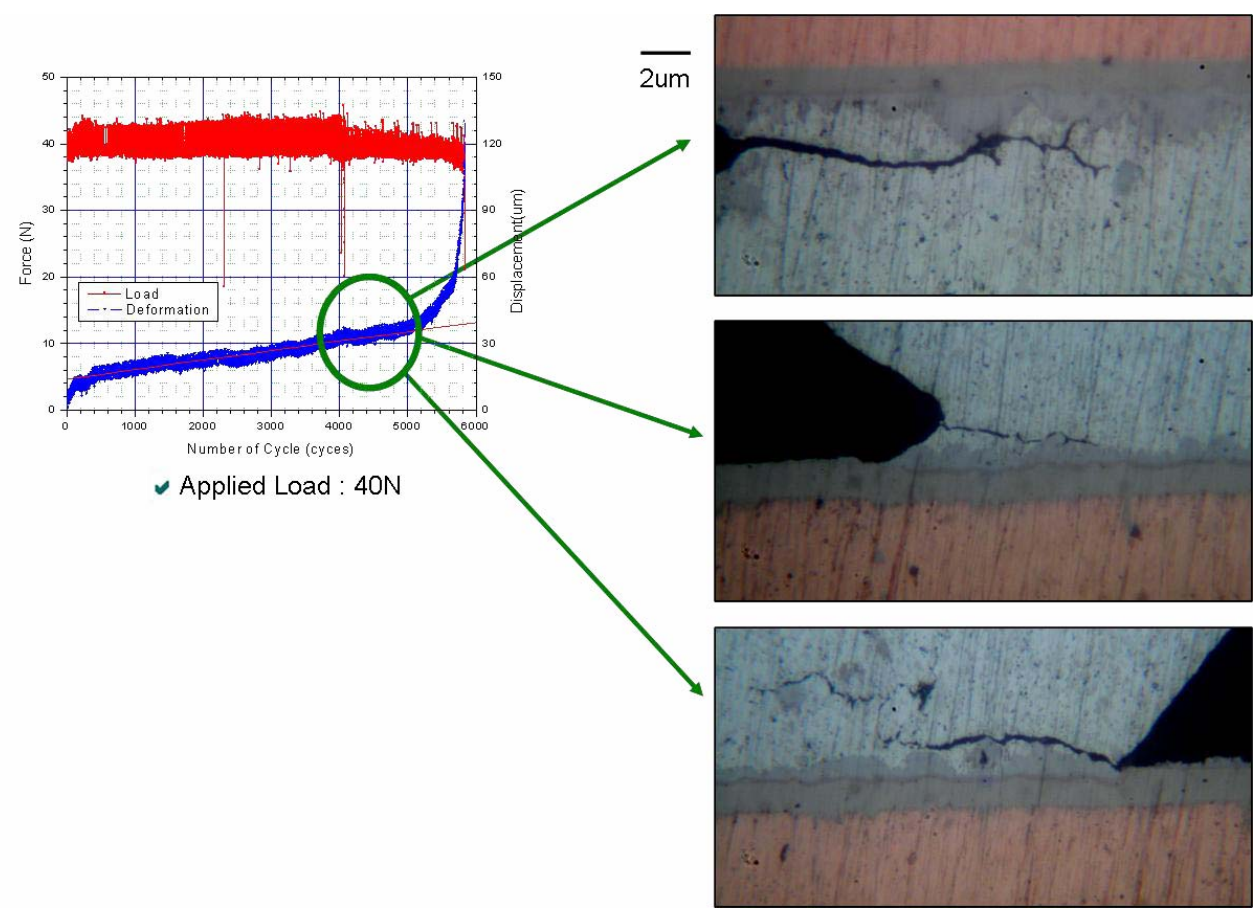

Fig. 10 Repeated impact load and corresponding deformation and cracks initiated at the corner of solder joints. 
The cracks do not propagate to intermetallic compound (IMC) or interface at the early stage. However as the crack propagate further, the load bearing area is reduced and when the stress reaches to the interfacial strength then the crack propagates to the interface. This mixed mode failure is shown in Fig.11. Failures in most of the impact fatigue loading showed this type of mixed mode failure of solder fatigue and interfacial fracture. When the impact stress was high at the beginning then interfacial fracture occurred. Fig. 12 shows the results of impact stress versus cycle to failure. Impact and fatigue has the linear relation except the high stress region where the brittleness of the interface makes the difference from fatigue failure.

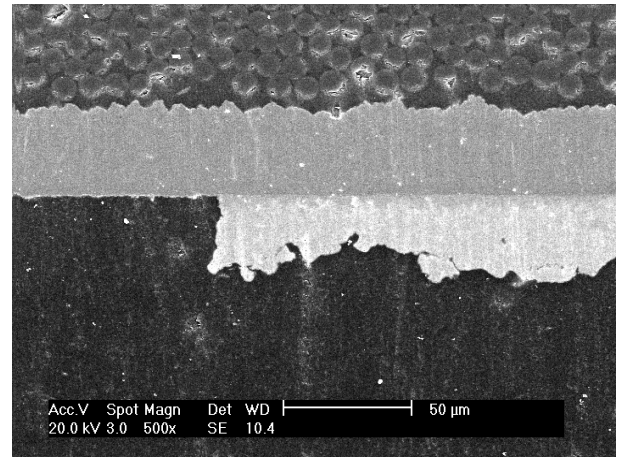

Fig. 11 Mixed mode fracture after 15000 cycles under impact loading of $40 \mathrm{~N}$.

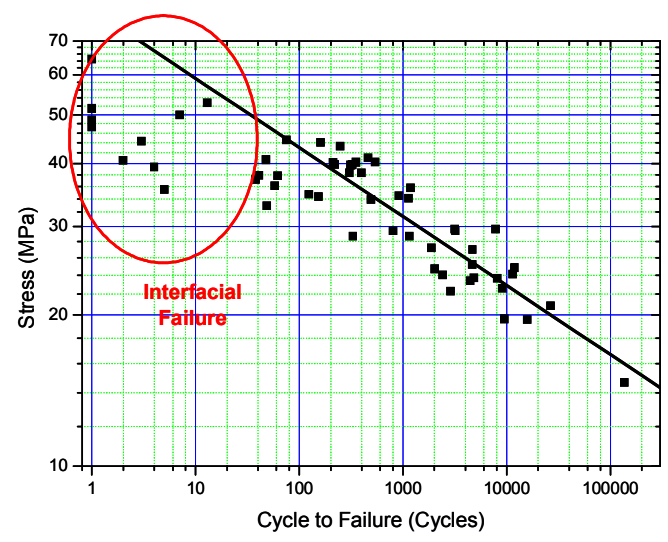

Fig.12 Results of impact stress versus cycle to failure.

\subsection{Comparison of Various Loading}

Results of various cyclic loading have been compared in terms of plastic strain energy density. Fig.13 shows the plastic strain energy density under various loading conditions ${ }^{(30)}$. Under the same plastic strain energy density, life under impact is the shortest, and isothermal cyclic bending load has the longest life. It is clear from this result that life prediction model should be constructed according to the load type. Fig.14 shows the fracture behaviors under mechanical, thermal cyclic, and impact loading. Fracture under mechanical fatigue show the crack propagation in the solder, and the fracture under impact show the interface cracking, and thermal cyclic loading shows the combination of solder and interface fracture.

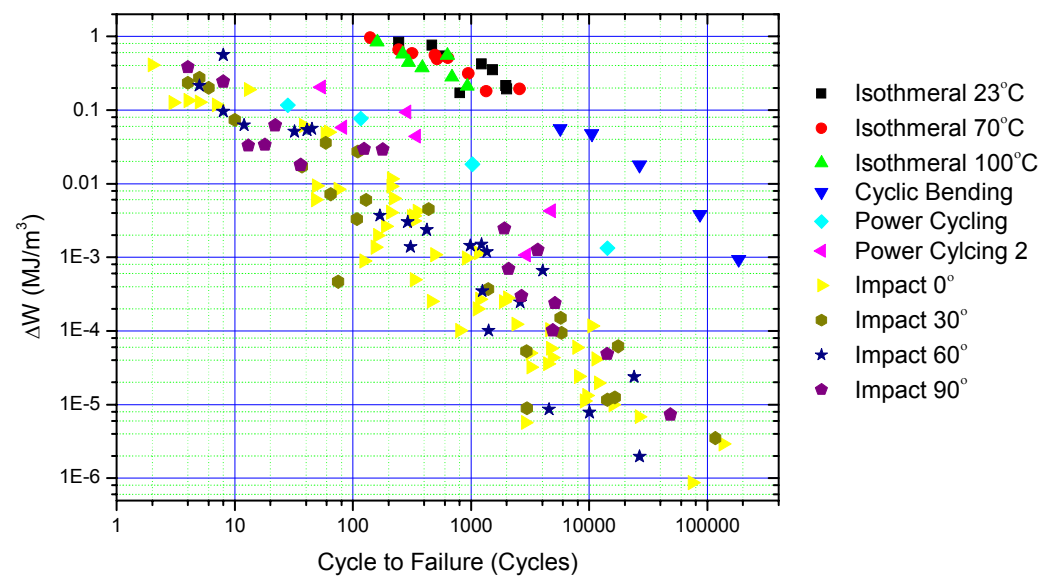

Fig.13 Plastic strain energy density under various loading conditions ${ }^{(30)}$ 


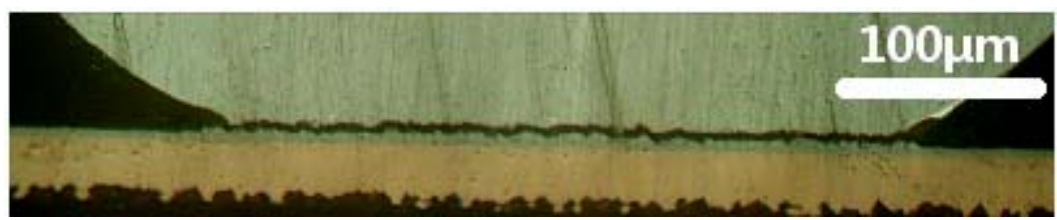

(a)

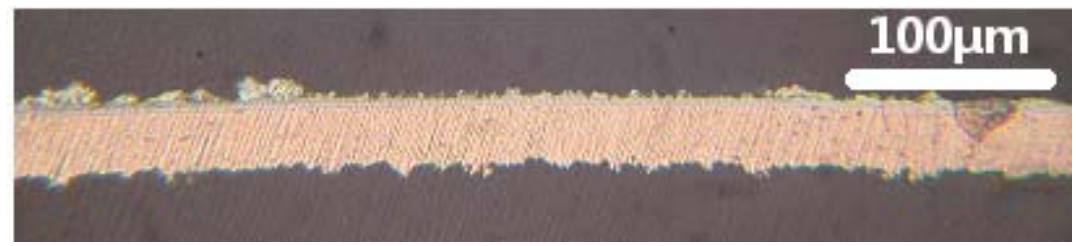

(b)

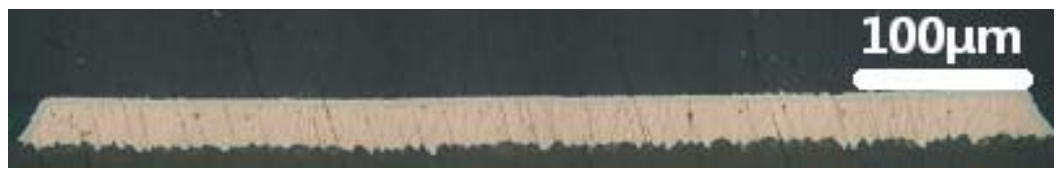

(c)

Fig.14 Fracture Behavior under various loading: (a) mechanical bending;

(b) Thermal cyclic loading; (c) impact loading.

\subsection{Cu/SnAg Double-bump Structure}

A thick $\mathrm{Cu}$ column based double-bump flip chip structure is one of the promising alternatives for fine pitch flip chip applications below $150 \mu \mathrm{m}$. For the reliability assessment of $\mathrm{Cu} / \mathrm{SnAg}$ double-bump flip chip assemblies shown in Fig. 15, thermal cyclic(T/C) tests were performed with two different $\mathrm{Cu}$ heights of double bump; $\mathrm{Cu}(60 \mu \mathrm{m}) / \mathrm{SnAg}(20$ $\mu \mathrm{m})$ versus $\mathrm{Cu}(80 \mu \mathrm{m}) / \mathrm{SnAg}(20 \mu \mathrm{m})$. The temperature range was between $-55^{\circ} \mathrm{C}(15$ $\mathrm{min})$ to $125^{\circ} \mathrm{C}(15 \mathrm{~min})$ during the thermal cyclic test. After 1000 thermal cycles, T/C failures occurred at some $\mathrm{Cu} / \mathrm{SnAg}$ bumps located at the edge and corner of chips. Thermal cyclic test results showed that $17 \%$ of the $\mathrm{Cu}(80 \mu \mathrm{m}) / \mathrm{SnAg}(20 \mu \mathrm{m})$ bumps at the edge of the chips were failed while $50 \%$ of the $\mathrm{Cu}(60 \mu \mathrm{m}) / \mathrm{SnAg}(20 \mu \mathrm{m})$ bumps at the edge of the chips were failed. Failure was defined $100 \mathrm{~m} \Omega$ of resistance of the connector. The detail failure site was identified at the Cu column and Si chip interface by Son et al. ${ }^{(18)}$.

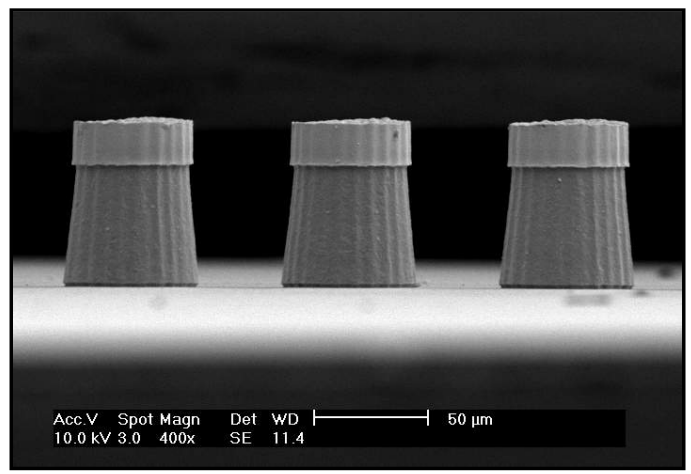

Fig. $15 \mathrm{Cu} / \mathrm{SnAg}$ double-bump structure for next generation packaging ${ }^{(18)}$.

To find the shear strain at the interface, optical method with Moiré Interferometry was used. Fig. 16 shows the U-displacement fields of the flip-chip assembly at $20^{\circ} \mathrm{C}, 75^{\circ} \mathrm{C}$, $100^{\circ} \mathrm{C}, 130^{\circ} \mathrm{C}$ and refined contour map by phase shifting technology ${ }^{(31)}$. Grating of 1200 
lines $/ \mathrm{mm}$ was attached at $130^{\circ} \mathrm{C}$ on the cross-section of the flip-chip assembly. The fringe resolution for this measurement is $0.417 \mu \mathrm{m} /$ fringe. From this fringe pattern we can calculate the strain distribution at the $\mathrm{Si}$ chip/ $\mathrm{Cu}$ column interface.

\section{(a)}

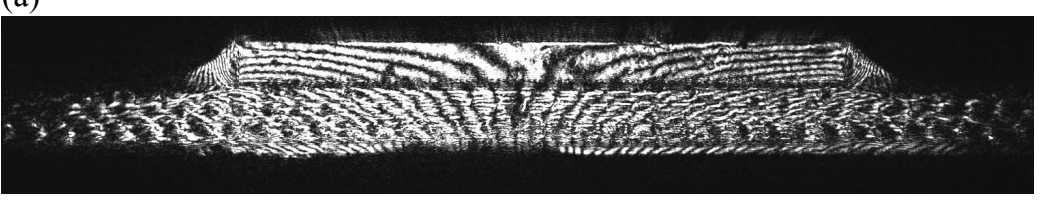

(b)

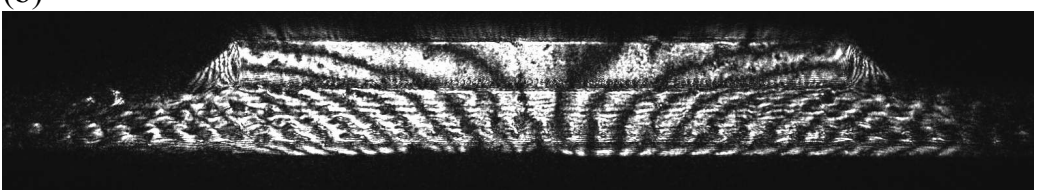

(c)

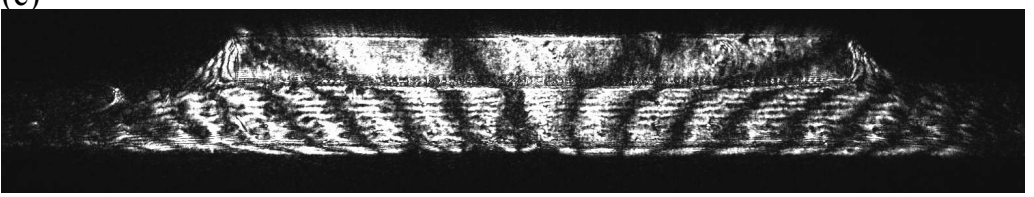

(d)

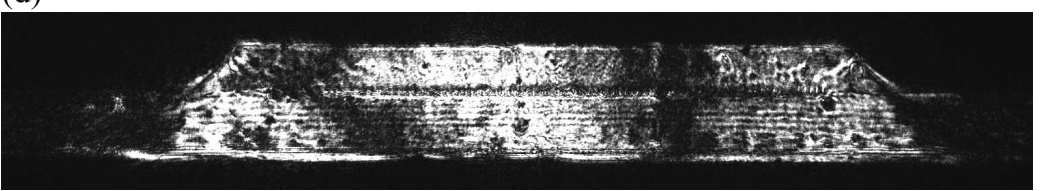

(e)

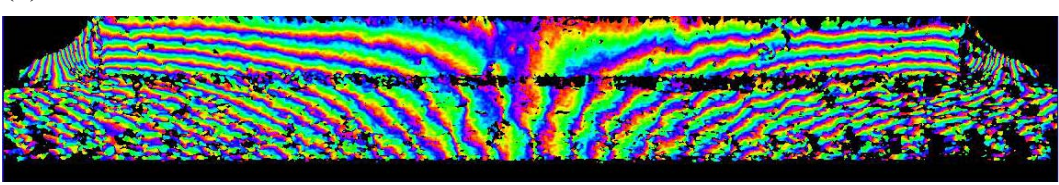

Fig.16 U-displacement of the flip-chip assembly by Moiré Interferometry: (a) $20^{\circ} \mathrm{C}$, (b) $75^{\circ} \mathrm{C}$, (c) $100^{\circ} \mathrm{C}$, (d) $130^{\circ} \mathrm{C}$, (e) refined contour map from phase shifting method. Grating attached at $130^{\circ} \mathrm{C}$ on the cross-section of the flip-chip assembly.

\section{High temperature behavior of metallic materials}

As the operating temperature of high temperature structures has increased to satisfy the demands for high efficiency and fast and mass transportation, the temperature variation from start-up to shutdown becomes larger and causes a large thermal stress on the structures. Type $316 \mathrm{~L}$ stainless steel, which has been favored as a structural material in several high-temperature components such as in the primary side of liquid metal cooled fast breeder reactor (LMFBR), stands as a prominent material for the next generation power facilities because of a good combination of its excellent high-temperature tensile and creep strength, corrosion resistance, and enhanced resistance to sensitization and associated intergranular cracking. It has been reported that, in the temperature range of $330-600^{\circ} \mathrm{C}$ where LMFBR operates, type $316 \mathrm{~L}$ stainless steel is susceptible to dynamic strain ageing(DSA) which may induce a significant change in material properties such as strength and ductility ${ }^{(20)(21)}$. The pronounced reduction of tensile ductility in the region of the DSA ${ }^{(21)}$ can induce a serious reliability problems in high temperature structures. DSA is the phenomenon of interactions between diffusing solute atoms and mobile dislocations during plastic deformation and depends on deformation rate and temperature, which govern the 
velocities of mobile dislocations and diffusing solute atoms, respectively. Detail mechanism of DSA is reported elsewhere ${ }^{(22)}$. Since the DSA influences the reliability of several other high temperature structures, other high temperature material such as 429EM ferritic stainless steel has been considered for the exhaust manifold of automobile. Nodular cast iron and gray cast iron are considered for the liner and cylinder in marine engine, and Inconell 718 and 630martensitic stainless steel are evaluated for the rocket engine part of the space launching system.

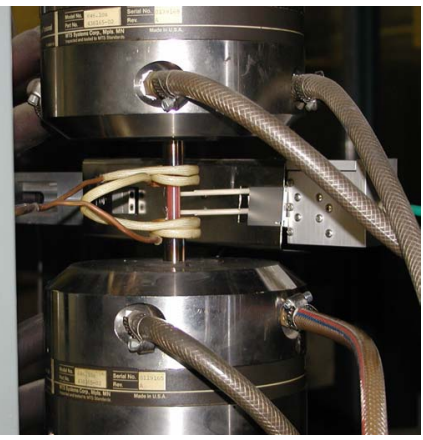

Fig.17 A high temperature testing system.

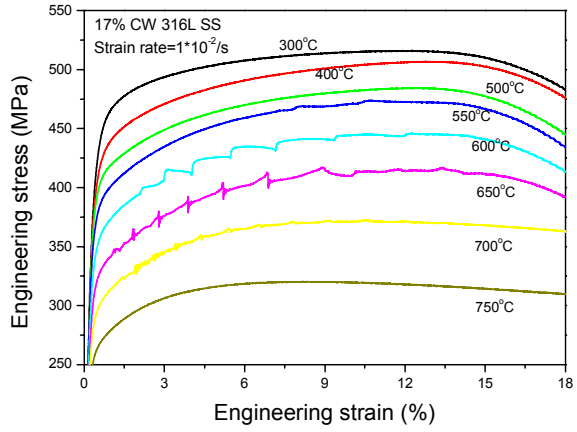

Fig. 18 Tensile tests results of $316 \mathrm{~L} \mathrm{SS}$.

High temperature material characterization has been performed with a closed-loop servo-hydraulic testing system. Fig.17 shows the hydraulic collet grips, induction heater, $12 \mathrm{~mm}$ gauge length of high temperature extensometer, k-type thermocouple. Tensile test and low cycle fatigue test for the high temperature materials were performed. Fig. 18 shows the stress-strain curves from tensile tests of $316 \mathrm{~L}$ stainless steel at various elevated temperature. Serration behavior is shown in dynamic strain aging region. The tensile fracture mechanism changed from the classic 'cup and cone' type fracture in the non-DSA regime to the 'cup and cone' fracture in the DSA regime that has a reduced and twisted fibrous zone, compared to that in the non-DSA, as shown in Fig.19.

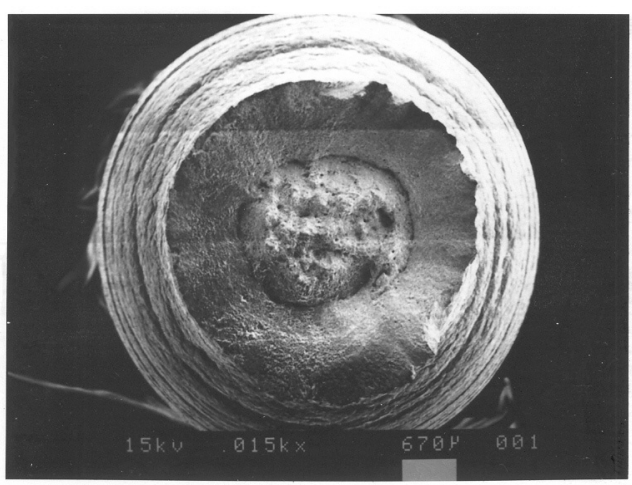

(a) Non DSA regime

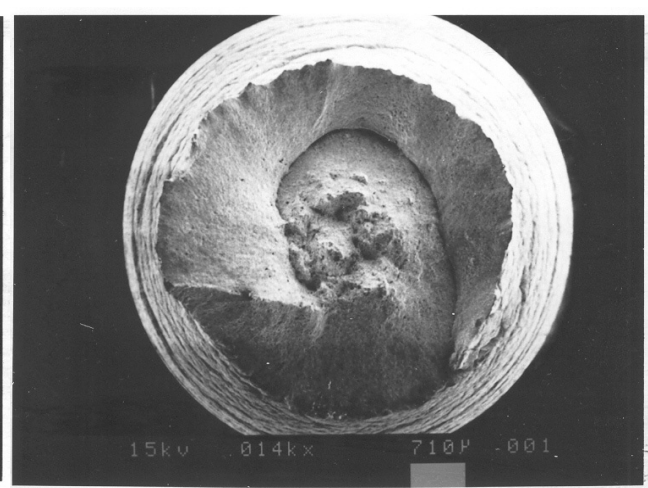

(b) DSA regime

Fig. 19 SEM micrographs of tensile fractured specimens of $316 \mathrm{~L}$ stainless steel:
(a) $200{ }^{\circ} \mathrm{C}, \dot{\varepsilon}=1 \times 10^{-4} / \mathrm{s}$
(b) $500{ }^{\circ} \mathrm{C}, \dot{\varepsilon}=1 \times 10^{-2} / \mathrm{s}$.

Low cycle fatigue tests were carried out in air in a wide temperature ranges from $20^{\circ} \mathrm{C}$ to $650{ }^{\circ} \mathrm{C}$ for type 316 stainless steel and 429EM ferritic stainless steel to check the effect of DSA on fatigue life. The clear life reduction has been observed at the DSA regime as shown in Fig. 20. When DSA occurs, cyclic hardening appears in the austenitic stainless steel ${ }^{\text {(20)(23) }}$ 
and in the ferritic stainless steel $^{(19)}$ and consequently rapid crack propagation. The DSA-induced inhomogeneity of deformation produces the multiple crack initiation (23), which results in the reduction of fatigue resistance.

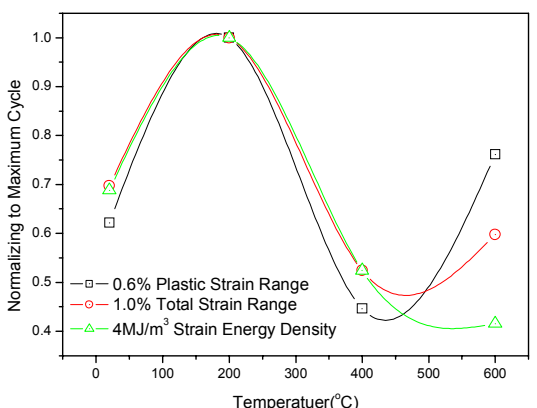

Fig.20 Relation between temperature and fatigue life.

In life prediction and design of high temperature structure, a constitutive relation for the cyclic inelastic response is needed. Phenomenological description of cyclic deformation using the overlay model was reported ${ }^{(24)}$. The modified overlay model showed a good capability for two types of stainless steel, 316L and 429EM at elevated temperatures. An energy-based fatigue damage parameter ${ }^{(32)}$ can be utilized in the life prediction of high-temperature structural materials for higher reliability.

\section{Summary}

Reliability assessments were performed for advanced structures such as MEMS and nano structures, electronics packaging, and high temperature structures. Advanced materials included electroplated nickel thin film for MEMS and nano structure application, lead-free solders and $\mathrm{Cu} / \mathrm{SnAg}$ double bump for microelectronics packaging application, and steels for nuclear and high temperature structures, super-alloys for space applications. The wide variety of advanced structures were handled with the same reliability assessment tools such as experiments under mechanical/thermal loading or relevant environment and compared with FEM analysis. Various testing machines have been developed for the experiments. All the reliability assessments reported here were performed with the hope to save human life in the long run.

\section{Acknowledgements}

This work has been supported by the core research program of National Research Foundation of Korea, and BK21 program of the Ministry of Education, Science and Technology of Korea. Contributions by Dr. D. C. Baek, Mr. M. Kim for thin film research, Dr. I. Kim, Dr. T. S. Park, Dr. S. Y. Yang, Dr. S. J. Ham, and Miss J. Y. Yoon for electronics packaging research, and Dr. S. G. Hong, Dr. K. O. Lee, Dr. S. S. Yoon for research on high temperature structures are greatly appreciated.

\section{References}

(1) Park, T.S., Baek, D.C., Lee, S.B., Sensors and actuators, A. Physical, Vol.115, No.1,2004, pp.15-22.

(2) Sharpe, W. N., Yuan, B., and Edwards, R.L., J. of Microelectromechanical Systems, Vol. 6, No. 3, 1997.

(3) Greek, S., "Tensile Testing of Thin Film Microstructures," Proceedings of SPIE, 
Vol.3224, Austin, Tx, U.S.A. 1997, pp.344-351.

(4) Oliver, W.C. and Pharr, G.M., J. Mater. Research,Vol.19, 2004, 3. (review article)

(5) Hong, S.G., Kim, M., Lee, S.B., J. of Microelectromechanical Systems, Vol.17, 2008, pp.1155 1163.

(6) Guo Y, Liu S., ASME J Electronic Packaging, Vol.120, 1998, pp.186-193.

(7) Han B, Guo Y, Lim CK, Caletka D.,ASME J Electron Packaging, Vol.118 1996, pp.157-163.

(8) Driel WD, Zhang GQ, Janssen JHJ, Ernst LJ, Su F, Chian KS, et al. Microelectronic Reliability,Vol.43, 2003, pp.765-774.

(9) Back, D.C., Doctoral thesis, DME, KAIST, Daejeon, 2009.

(10) Ham, S.J., and Lee, S.B., Journal of Electronic Packaging, Vol. 125, 2003, pp. 282 288.

(11) Park, J.H., and Lee, S.B., JSME international- J. of Solid Mechanics and Materials Engineering, Vol. 2, No. 6, 2008, pp.822-830.

(12) Yoon, J.Y., Kim, I., and Lee, S.B., Trans. of the ASME- P- J. of Electronic Packaging, Vol.131, No.2, 2009, pp.021012.

(13) Lee, K.O., Yu, J., Park, T. S., and Lee, S.B., Journal of Electronic Material, Vol.33, No.4, 2004, pp.249 257.

(14) Kim, I., Lee, S.B., IEEE Transactions on Components and Packaging Technologies, Vol.31, No.2, 2008, pp. 478 484.

(15) Kim, I., Lee, S.B., IEEE Transactions on Components, Packaging and Manufacturing Technology - Part B, Vol.32, No.3, 2009, pp.542 549.

(16) Yang, S.Y., Kim, I., Lee, S.B., IEEE Transactions on Components and Packaging Technologies, Vol.31, No.1, 2008, pp.3 12.

(17) Kim, I and Lee, S.B., IEEE Transactions on Components and Packaging Technologies, Vol.31, No.2, 2008, pp.478 484

(18) Son, H.Y., Kim I, Lee, S.B, Jung, G.J., Park, B.J., and Paik, K.W., J. Applied Physics, Vol.105, 2009, pp. 013522.

(19) Lee, K.O., Hong, S.G., Yoon, S.S., and Lee, S.B., International Journal of Fatigue, Vol.27, No.10/12, 2005, pp.1559-1563.

(20) Hong, S.G., and Lee, S.B., International Journal of Fatigue, Vol. 26, No. 8, 2004, pp. 899-910.

(21) Hong, S.G., and Lee, S.B., Journal of Nuclear Materials, Vol. 328, No. 2-3, 2004, pp. 232-242.

(22) Hong, S.G., Lee, S.B., J. of Nuclear Material, Vol.340, Issues 2-3, 2005, pp.307-314.

(23) Hong, S.G., Lee, K.O., and Lee, S.B., International Journal of Fatigue, Vol. 27, No.10/12, 2005, pp.1420 -1424.

(24) Yoon, S.S., Hong, S.G, and Lee, S.B., Materials Science and Engineering A, Vol. 364 2004, pp. 17-26.

(25) Basquin, O. H., Am. Soc. Test. Mater. Proc., Vol.10, 1910, pp. 625-630.

(26) Morrow, J., Fatigue Design Handbook, Advances in Engineering, Vol. 4, Society of Automotive Engineers, Warrendale, Pa., Sec. 3.2, 1968, pp.21-29.

(27) Bannantine, J.A., Comer, J.J., and Handrock, J.L., "Fundamentals of Metal Fatigue Analysis," Prentice Hall, New Jersey, 1990.

(28) Chen, Y. S., Huang, Y. L., Kuo, C. H., and Chang, S. H., Int. J. Mech. Sci., Vol. 49, No. 6,2007, pp. 733 740.

(29) Lee, S.B., Kim, I., and Park, T.S., Int. J of Fracture, Vol. 150, 2008, pp. 91-104.

(30) Kim, I., Doctoral thesis, DME, KAIST, Daejeon, 2008.

(31) Yang, S.Y., and Lee, S.B., Optics and Lasers in Engineering, Vol. 43, No.6, 2005, pp.721-736.

(32) Lee, K.O., Hong, S.G., and Lee, S.B., Materials Science and Engineering A, Vol.496 2008, pp.471-477. 